\title{
Investigating the Impact of Leadership Behaviour on Conflict and Employee Engagement in Nigerian Universities
}

\author{
Ezekiel O. Adeleye \\ Department of Business Administration \\ Ajayi Crowther University \\ Oyo, Oyo State, Nigeria. \\ Yahaya Y. Yusuf \\ Lancashire School of Business and Enterprise \\ University of Central Lancashire \\ Preston PR1 2HE, U.K
}

\begin{abstract}
This study examines the impact of leadership behaviour on employee engagement in Nigerian universities using conflict as a moderating variable. It uses the quantitative method and a survey by questionnaire to collect perceptual data from a sample of 406 employees. Factor analyses reduce the study variables and generate eight empirical constructs: (1) Leadership behaviour- Transactional, Managerial, Collegiate and Laissez-faire; (2) Conflict- Interpersonal enmities and Career frustration; and (3) Employee Engagement-Motivation and Satisfaction. Regression and path analyses reveal several direct and indirect relationships amongst the factor dimensions. All the leadership behaviours exercise direct impacts on the engagement categories, but with conflict as a moderator, the effects were watered down to nought. Sub-samples mean difference test results were not significant. Prior research has identified the positive impact of leadership behaviour on employee engagement but the attrition effect arising from conflict as a moderator variable was yet to receive significant attention.
\end{abstract}

Keywords: leadership behaviour, Conflict, Engagement, Nigerian universities, Path analysis, Empirical

\section{- Introduction}

Given its importance in influencing and enlisting subordinates' support for greater accomplishments, leadership behaviour is a crucial factor in organisational life. This is more so for universities as labour intensive and highly intellectual organizations, even as human beings (students) constitute the in-process material (Adeleye,2015). Hence, leadership responsibilities need to be widely spread or distributed across a wider range of employee cadres including faculty officers and teachers as front-line executives. As such, expected is a relational web of leadership responsibilities across the rank and file. From the subordinates' perspectives at every cadre, the appropriateness of the behaviours adopted would be crucial to reducing conflicts, especially their transaction and signalling costs (Williamson, 1975; Bergh, Ketchen, Boyd and Bergh, 2010). However, leadership studies extending to the lower ranks and focusing on the subordinate's opinion of the immediate supervisor's behaviour are rare (Offord, Gill \& Kendal, 2016). This is even as reports abound that the high incidence and intensity of work process conflicts on employee engagement, team effort and performance outcomes is the greater challenge of leadership especially in Nigeria universities (Ebura, Udida \& Curşeu, 2009; Offord, Gill \& Kendal, 2016). This accounts for issues of low employee morale and engagement, the indicators inclusive of absenteeism and uncared attitudes, high staff turnover, academic corruption, poor quality of graduates, and low international reckoning (Okebukola, 2018).

Since 1948 when the first Nigerian university was founded, the widespread agitation for enhanced access and highlevel manpower development has led to astronomical increase in the number of universities, presently 165 out of which 75 are privately owned. As well, student enrolment has grown from just over 2,000 in 1962 to about 1.9 million in July 2017 (Obasi, 2007; Ebura, et.al, 2009; Ogunruku, 2016; Okebukola, 2018). The pressures for growth would continue as over two million candidates applied for admission for the 2018/2019 academic year. This is even as problems of inadequate funding, student cultism, deteriorating infrastructure, examination malpractices, labour strikes, academic corruption and poor international reckoning are rife (Odia and Omofonmwan, 2007; Salako, 2014). The growth-induced challenges have been exacerbated by national leadership failures and the culture of corruption; which infringe on the performance of most Nigerian institutions (Odia and Omofonmwan, 2007; Okebukola, 2018). 
Accordingly, Nigerian universities have a rich history of conflicts induced either externally via matters of political appointments, poor funding, wage legislation and labour disputes or internally through students unrest or work related frictions amongst staff, even as individuals and work groups like faculty and staff appear most polarised (Raeve, Jansen, Brandt, Vasse, \& Kant, 2008; Ndum \& Okey 2013). Within this context, the challenge of appropriate leadership for conflict reduction becomes more important, given that Nigerian universities, especially the public-owned ones experience the greatest instability (strikes and closures) world-wide, in spite of pressures to produce graduates of greater entrepreneurial and employability skills and competencies (Ebura, Udida, Ekpiken and Bassey, 2009; Adeleye, 2015). Similar circumstances have been reported for Syrian, Saudi Arabian and many African universities (Dalati, 2014). Hence, a call has been made for continued exploration and nurturing of appropriate leadership, conflict and engagement frameworks across the rank and file, different from those developed in the western nations where financial, political, ownership and other externally imposed exigencies are less inhibitive (Ebura et.al., 2009; Daramola \& Amos, 2016).

\section{- Leadership Theories}

Leadership theory is a discipline that focuses on finding out what exactly makes a leader effective and successful (Northouse, 2004; Health and Safety Executive, 2012). It has a long history, starting in the 19th century with the great man theory of organisational success (Grint, 2015). Now seemingly old fashioned, it remains relevant in political and bureaucratic organisations (Bryman, 1992; Ojo, 2009). From the 1930s, scholars shifted attention to the behaviour of leaders in interacting with the followers and involving them in getting things done (Meindl, 1995).

The thesis surfaced thereafter that leader behaviour could be context-specific. Hence, the emergence of the situational / contingency theories by which attention shifted to the leadership environment, with the prescription that leaders change their behaviour in response to the general work context (Northouse, 2004). Following closely, the path-goal theory originated, founded on the principles of leadership deeds that promote subordinate involvement, motivation, commitment and satisfaction en-route organisational goal attainment (1996; Northouse, 2004). The stage therefore became set for a give and take, goal-driven contractual relationships in the dynamic leader-follower process at work, code-named the transaction theory of leadership (Bergquist, 1992; Bass and Avolio, 2003; Kihara, Bwisa, \& Kihoro, 2016). Transactional leadership is characterised by a framework of give and take performance enhancing rewards used as the basis for ensuring subordinates' commitment and loyalty. Closely related is the path-goal theory (Health and Safety Executive, 2012; Grint, 2015). In Nigeria, it is common knowledge that routine and mandatory contractual obligations on salaries, allowances and other perquisites often get derailed due to funding and other externally-induced failures (Ebura, Udida, Ekpiken, \& Bassey, 2009). Moreover, as the university system is often characterized by large size, formal structure, relatively undifferentiated goals and mass production orientated, the space to apply meaningful, symbolic and "guided missile" type of incentives within the framework of transactional leadership is limited (Adeleye, 2015).

Next, the vision-driven transformational theory emerged (Bass 1985; Yammarino \& Bass, 1990; Hemsworth, Muterera, \& Baregheh, 2013). It focuses on protecting and strengthening the organisational commonweal through vision articulation, intellectual stimulation, and idealized / inspirational motivation of subordinates (Baatz, 1993; Bass \& Avolio, 1995; Grint, 2015). Transformational leadership may not be manifest in the highly elitist university environment where supervisory initiatives could be derided as manipulative and self-serving epistles, especially in the Nigerian cultural context.

As the factory system gave way to more knowledge work and less tangible results, the followership theory emerged. Followers were to take greater responsibility, be more role articulated and independent, but without being disrespectful (Vroom \& Yetton, 1973; Zimmerman, 1999). On the basis of two dimensions of relative activism and critical thinking, five types of followers have been discussed widely. They are: alienated (passive/critical), sheepish (passive/uncritical), yes people (active/uncritical), survival players (better be safe that be sorry), and effective followers (active /critical) (Kelley, 1992; Chaleff, 1993; Baatz, 1993; Dess and Picken, 2000).

Leadership will be more positive if the followership is effective but effective followers may be hard to come by especially in the African and Arabian context, characterized by a large power distance between the leader / manager and the follower (Luthans \& Doh, 2009). As such, reports abound on effective followers being helplessly turned into alienated or sheepish followers in situations such as where an inept leader feels insecure with the hard-work, initiatives, superior argument and sincerity of an effective follower (Chaleff, 1995; Dess \& Picken, 2000).

The theory of distributed or shared leadership across the rank and file has also emerged and gained momentum as a means of winning followers' confidence especially in large organizations (Bergmann, Hurson, \& Russ-Eft, 1999; Papalexandris \& Galanaki, 2009; Grint, 2015). 
It means that everyone is a leader within a seamless chain of collaborative stakes and internal market responsibilities, that minimize all forms of transaction and signalling costs in work processes relationships (Adeleye, 2015). The distributed approach appear similar to the laissez faire and collegiate leadership inclinations often associated with universities' rationality and superior argument (Bergquist, 1992).

Specifically for the academy, some theoretical frameworks have been proposed and justified. Bolman \& Dean (2003) proposed a four-frame model of educational leadership namely structural, human resource, political and symbolic; which were validated in the study of a private university in Malaysia (Tan, Hee, \& Piaw, 2015). The symbolic frame appears closer to the transformational model of leadership; which is anchored on intellectual stimulation but may not be typical of the Nigerian university system where vision, mission and programmes are not manifestly differentiated. In contrast, the structural (perhaps managerial) and the political frames, which Bolman \& Dean (2003) associated with power struggles may be exemplified in the Nigerian universities as the major cause of conflicts, low employee engagement and high exit intentions.

Berquist (1992) also discussed a four-frame interactive model of leadership culture in colleges and universities namely collegiate, managerial, developmental and negotiating. Anyone of them could be the dominant culture; which exists in parallel but to different degree, and interacts with the other three cultures. All the four cultures, especially the collegiate and developmental could be more ideal for conflict reduction; but nurturing them within the Nigerian university environment might be problematic without requisite levels of maturity, autonomy, adequate funding and staff/student commitment (Ebura et.al., 2009; Asawo, 2011).

In the light of the fore-going discussion of the relative merit of leadership theories specific to the university setting, this study adopts the behavioural and distributed approaches; which are rich in contingency alternatives as well as greater responsibilities at all levels (Bergmann, et.al., 1999; Curseu, 2011; Kihara, Bwisa, \& Kihoro, 2016). Leadership behaviours would expectedly include the transformational, transactional, bureaucratic, laissez faire and collegiate (shared) behaviours. However, the specific Nigerian university-form could reflect cultural characteristics such as the high power distance between leaders and followers rather than the academy culture of rationality, freedom and autonomy (Bergquist (1992; Luthans \& Doh, 2009). Based on the foregoing evidence of the rich range and merit of leadership behaviours, the first hypothesis of the study is:

Hypothesis 1: A wide range of leadership behaviours are not discernible in the Nigerian universities.

\section{- Conflict And Employee Engagement}

All human organisations experience conflicts of varying magnitudes; the consequences of which Edwards collectively describes as structural antagonism (Fincham \& Rhodes, 1992, p.252). Conflict can be defined as overt or covert disparity in perspectives, behaviour or attitude between two or more parties, resulting in deliberate efforts to block or frustrate the endeavours, interests or goals of one another (Offord, Gill, \& Kendal, 2016; Raeve, et.al., 2008). It originates majorly from differences in perceptions and attitudes, task inter-dependence, conflicting goals/priorities, disparities in time orientation, resource limitations and infractions by stakeholders in the internal and external environments (Curseu, 2011). Often perceived as disruptive and inhibitive of progress, it could however expose important problems, force new solutions and lead to better results if well managed (Shetach, 2012). An isolated and covert conflict becomes overt and diffused if not promptly neutralised, and hence, its direct and indirect effects as well as the immediate and long term costs could escalate. Therefore, managers are known to spend over forty percent of their time attending to conflicts (Raeve, et.al., 2008).

Conflicts, especially intra group and boss-subordinate conflicts within an academic department or between say the vice chancellor and the registrar of a university could remain covert for years but be most devastating in their primary and secondary effects (Ndum \& Okey, 2013). The work place could become ludicrous and hostile, even as quit intensions amongst several other negative tendencies in conflict situations would diminish employee engagement and productivity (Fincham \& Rhodes, 1992; Barbuto, Phipps, \& Xu, 2010; Curseu, 2011). Hence, we propose:

Hypothesis 2: Nigerian universities are not characterised by a high incidence of conflicts.

Employee engagement (EE) is an encapsulated measure of commitment, effectiveness, motivation and job satisfaction (Papalexandris \& Galanaki, 2009; Xu \& Thomas, 2011). An engaged employee is the one who is fully absorbed and enthusiastic about their work, and also takes positive action to further the organization's reputation and interests, especially in turbulent times (Bolman \& Deal, 2003; Catteeuw, Flynn, \& Vonderhorst, 2007; Ahmed \& Dajani, 2015). According to Wikipedia, EE is a property of the relationship between an organization and its employees. Clearly, sustainable ownership of this property is realisable through conflict deterring leadership behaviours (Xu \& Thomas, 2011; Offord, et.al., 2016). Hence, work units in the top quartile in EE were found to outperform the bottom quartile by between 10 and 70 percent on a dozen performance measures (Reilly, 2014). 
However, wherever and whenever conflict persists, it creates an atmosphere of concealment, disrespect and animosity that can potentially lower work engagement and call into question the leaders' ability to deliver results (Xu \& Thomas, 2011; Northouse, 2004; HSE, 2012). Career-based conflicts, arising from externally-induced financial and policy inadequacies will be more manifest in Nigerian universities by way of failed promises, delayed promotions, declining infrastructure decay, staff and student agitations. Obviously, workers experiencing animosity and constant obstruction with their supervisors are less likely to be satisfied and emotionally attached to their jobs. Effective leadership that promotes successful conflict prevention and resolution will therefore be crucial to minimising the frequency, magnitude and consequences of conflicts on employee engagement and loyalty (Curseu, 2011; Montes, Rodriguez, \& Serrano, 2012; Offord, et.al, 2016). Accordingly, Hypotheses 3 and 4 explore the impact of leadership on employee engagement and the moderating influence of conflict on the relationship.

Hypothesis 3: $\quad$ Leadership behaviour has no impact on employee engagement.

Hypothesis 4: $\quad$ Conflicts do not affect the relationship between leadership behaviour and employee engagement.

It was argued earlier that African and Arabian universities including the privately owned ones are largely undifferentiated in terms of curriculum, faculty and management structure. Accordingly, the fifth hypothesis of the study aims to explore the validity of the findings across the universities, faculty/staff categories and employee cadres. Hence, we state as follows.

Hypothesis 5: $\quad$ Employee perceptions on leadership behaviour, conflict and engagement do not vary widely across the public and private universities and employee categories in Nigerian universities.

\section{- Materials And Method}

\subsection{Objectives and Hypotheses}

The study investigates the nature of leadership behaviour and its impact on employee engagement using conflict as a moderating variable. It also seeks knowledge of variations in perceptions on the three conceptual pillars of leadership behaviour, conflict and engagement across the major types of universities and demographic sub-samples of employees.

\subsection{Research Design}

The study adopted the positivist paradigm guided by a set of hypotheses specified in the Null form, structured and justified around a review of related literature (Cresswell, 2008). Research hypotheses were crafted based on the theoretically expected relationships amongst the major themes. Field studies involved the use of a survey by questionnaire to collect data in order to test the hypotheses proposed.

\subsection{Population and Sample}

The study population were all university employees in Nigeria. However, funding restrictions compelled the opportunistic choice of a cluster of universities closer to the researchers' base in the south-west region of Nigeria. The only exception was just one university out of the many that were sampled from each of the middle belt and south-south regions, whose workers responded to the on-line questionnaire. Our field work revealed that most Nigerian universities have no operational website, e-mail systems and employee telephone databases, just as the postal system remains comatose. However, efforts were made to ensure balance in the number of respondents across major departments, units and staff categories. Bottom line and non-career workers such as visiting lectures, porters, security guards and caterers were deemed unusable and excluded.

\subsection{Instrument Development and Data Collection}

The research questionnaire consisted of fifty instruments: forty on leadership and ten on each of conflicts and employee engagement. Each question had perceptual response options on the six-point Likert scale ranging from Almost never (1) to Always (6). The full range leadership scales and the academy-specific scales (Bergquist, 1992; Bass \& Avolio, 1995) were modified and reduced to twenty-nine in order to be context specific and eliminate duplication. The twenty questions on conflict and engagement were extracted from several works (Curşeu, 2011; Ndum and Okey, 2013). A total of 720 hard and on-line copies of the questionnaire were distributed, 418 were returned and 402 were found usable. The response and useful response rates were 58.06 and 55.83 percent respectively.

\subsection{Methods of Data Analysis}

The Statistical Package for Social Sciences (SPSS 16.0) for Windows was used for data analysis. The alpha reliability test procedures were first applied to measure the extent to which the questionnaire items were effective measures of the conceptual constructs of leadership and conflict. 
This was followed by exploratory factor analysis as the means of reducing the leadership, conflict and work engagement scales to a few core dimensions. Eigen values greater than one was used as the criterion for factor retention, and the solutions were rotated using the Varimax option. Variable coefficients less than 0.30 were suppressed to enhance model interpretation.

Next, correlation and regression tests were used to estimate the impact of the leadership dimensions on conflict and employee engagement as dependent variables. The standardized scores of factor analysis were used for the regression tests. Reported are the $\mathrm{R}^{2}$ and F-ratio as measures of model fit, the $B$ statistic of the predictive power of each independent variable, the t-test of variance and the significance levels. Finally, analysis of variance (ANOVA) was applied to test the results across sub-samples of respondents. Significant differences in sub-samples mean scores and the F-ratio of explained and unexplained effects within and across the sub-samples were used.

\subsection{Data Validity and Reliability Tests}

The validity test aimed to ensure the measurement accuracy of instruments, so that research processes and results are repeatable and applicable without contextual limitations. Hence, the study was guided by a review of related works and a set of Hypotheses derived there from. The questionnaire contained some control questions while some interviews were held with some senior management staff in three respondent universities. A pilot test was conducted by which some data considered problematic were screened out. Furthermore, to ensure that results are chance-proof, sub-samples of early/late respondents and even/odd numbered returned questionnaires were tested for significant differences.

The Alpha test procedure was used to check for internal consistency (Papalexandris \& Galanaki, 2009; Adeleye, 2015). For the leadership 6-point Likert scales, Cronbach's Alpha, grand mean and variance were 0.954, 4.055 and 0.148 respectively. The single measures intra-class correlation was 0.418 at $\mathrm{p}=0.00$, with an F-value of 16.054 at $\mathrm{p}=0.00$. Repeated for the conflict and employee engagement scales. The results suggest that the research instruments do not have the same mean, and that they varied widely and interacted harmoniously.

\section{- Results}

\section{- Demographic Characteristics of Respondents}

Table 1. Demographic characteristics of respondents

\begin{tabular}{|c|c|c|c|c|c|}
\hline Demographic bases & Frequency $^{1}$ & $\%$ & & Frequency $^{1}$ & $\%$ \\
\hline Age & & & Staff category & & \\
\hline Up to 30 years & 68 & 16.9 & Teaching staff & 210 & 52.1 \\
\hline $31-40$ years & 173 & 42.9 & Admin. / Registry staff & 124 & 30.8 \\
\hline $41-50$ years & 99 & 24.6 & Laboratory / Library staff & 24 & 6.0 \\
\hline $51-60$ years & 32 & 7.9 & Works and Services staff & 8 & 2.0 \\
\hline Over 60 years & 15 & 3.7 & Others & 23 & 5.7 \\
\hline Gender & & & Staff status & & \\
\hline Male & 260 & 64.5 & Principal staff & 16 & 4.0 \\
\hline Female & 135 & 33.5 & Senior staff & 273 & 67.7 \\
\hline Marital status & & & Intermediate staff & 42 & 10.4 \\
\hline Single / Divorced & 91 & 22.6 & Junior staff & 51 & 12.7 \\
\hline Married & 304 & 75.4 & & & \\
\hline Highest level of education & & & Years in this university & & \\
\hline Diploma / Certificate & 20 & 5.0 & Up to two years & 85 & 21.1 \\
\hline Graduate & 125 & 31.0 & $2-5$ years & 150 & 37.2 \\
\hline Master's /post-graduate & 147 & 36.5 & $6-10$ years & 102 & 25.3 \\
\hline Ph.D. & 100 & 24.8 & Over 10 years & 54 & 13.4 \\
\hline Others & 6 & 1.5 & & & \\
\hline \multicolumn{6}{|l|}{ Type of University } \\
\hline Federal & 83 & 20.6 & & & \\
\hline State & 86 & 21.3 & & & \\
\hline Private & 233 & 57.8 & & & \\
\hline
\end{tabular}

Source: Survey data, 2018

${ }^{\mathrm{I}}$ Calculations exclude missing data.

Table 1 reports the demographic composition of respondents on the basis of age, gender, marital status, education, years served, staff category and status. The respondents were fairly spread across the categories, as for example, private and public universities in the study were 42 percent and 58 percent respectively. 


\subsection{Leadership Behaviours.}

Exploratory factor analysis identified four leadership behaviours in twenty two iterations within which $64.27 \%$ of total variance was explained. On the basis of the variable loadings unique to each identified factor, they were interpreted as the transactional, managerial, collegiate and laissez faire behaviour styles. Table 2 shows the behaviour scales in Column 1 and the factors / variable loadings in Columns 2-5. The first style- transactional- was so named because of the strong weights associated with engaging staff (.668), honest (.642) and decisive (.610). This suggest that leaders honour agreements, comply strictly with procedures and processes, and may not mind reading / invoking the "riot act". The second component is managerial due to the high and isolated weight of coaching and mentoring (.808), self control (.511), compassion (.645) and well organized (.510). The third is the collegiate model, populated by: the acceptance of superior argument (.608), community orientation (.627), network orientation (.658), uniquely approachable (.653), and consults (.564). This model defines the university as an intellectual community of equally well educated colleagues, led by the virtues of faculty supremacy, superior argument, community life, academic freedom and autonomy. The fourth model is jointly exemplified by a laissez faire kind of "if not broke, do not fix" (.852) approach and a vindictive (.866) and punitive focus on subordinates errors and failures. The results provide the evidence that Nigerian universities parade a wide range of leadership behaviours including the collegiate, transactional, managerial and laissez faire. As such, there is no basis to accept Hypothesis 1.

Table 2. Factor analysis of the leadership behaviour scales.

\begin{tabular}{|c|c|c|c|c|}
\hline Leadership Behaviour Scales & $\begin{array}{c}1 \\
\text { Transactional } \\
\end{array}$ & $\begin{array}{c}2 \\
\text { Managerial }\end{array}$ & $\begin{array}{c}3 \\
\text { Collegiate }\end{array}$ & $\begin{array}{c}4 \\
\text { Laissez faire }\end{array}$ \\
\hline Engaging & .668 & .349 & .323 & \\
\hline Honest & .642 & & .445 & \\
\hline Decisive & .610 & .497 & & \\
\hline Friendly & .602 & .394 & .331 & \\
\hline Selfless & .579 & .329 & .389 & \\
\hline Inspirational & .558 & .487 & .442 & \\
\hline Self-control & .547 & .511 & .331 & \\
\hline Humble & .541 & .317 & .387 & \\
\hline Motivates & .539 & & .507 & \\
\hline Incubates employees & .535 & .312 & & \\
\hline Grants autonomy & .516 & .418 & & \\
\hline Embraces diversity & .482 & .303 & .407 & \\
\hline Anticipates and acts & .463 & .460 & .453 & \\
\hline Coaches and mentors & & .808 & & \\
\hline Change driven & & .794 & & \\
\hline Relates well & & .738 & & \\
\hline Compassionate & .434 & .645 & & \\
\hline Well-organized & .460 & .510 & .335 & \\
\hline Responsive & & .326 & .667 & \\
\hline Network oriented & .314 & .366 & .658 & \\
\hline Approachable & & & .653 & \\
\hline Community oriented & .373 & .353 & .627 & \\
\hline Accepts superior argument & .328 & & .608 & \\
\hline Performance driven & .548 & & .567 & \\
\hline Consults & .457 & .319 & .564 & \\
\hline Visionary & .432 & .450 & .523 & \\
\hline Courageous & .349 & .413 & .518 & \\
\hline Vindictive & & & & .866 \\
\hline Laissez faire & & & & .852 \\
\hline Total variance explained (64.28\%) & 20.154 & 18.626 & 18.483 & 7.014 \\
\hline
\end{tabular}

Source: Survey data, 2018

\section{- Conflict}


Table 3. Descriptive statistics of the Conflict measurement scales.

\begin{tabular}{llllllllll}
\hline & & & & & Mean & Std & & Skewness & Kurtosis \\
& $\mathrm{N}$ & Range & Min Max & (Std. error) & Dev. & Variance & (Std. error) & (Std. error) \\
Inter-personal enmities & 263 & 5 & 1 & 6 & $2.35(.064)$ & 1.044 & 1.091 & $.556(.150)$ & $-.063(.299)$ \\
Lack of Co-operation & 261 & 5 & 1 & 6 & $2.28(.069)$ & 1.117 & 1.248 & $.897(.151)$ & $.596(.300)$ \\
Unhealthy Competition & 260 & 5 & 1 & 6 & $2.37(.082)$ & 1.319 & 1.739 & $1.003(.151)$ & $.370(.301)$ \\
Withholding vital information & 260 & 5 & 1 & 6 & $2.22(.076)$ & 1.218 & 1.482 & $.887(.151)$ & $.062(.301)$ \\
Opposing views hinder effort & 260 & 5 & 1 & 6 & $2.53(.071)$ & 1.147 & 1.315 & $.750(.151)$ & $.618(.301)$ \\
Employees avoid one another & 261 & 5 & 1 & 6 & $2.55(.075)$ & 1.207 & 1.456 & $.665(.151)$ & $.108(.300)$ \\
Lack of trust and belief & 262 & 5 & 1 & 6 & $2.60(.078)$ & 1.267 & 1.606 & $.672(.150)$ & $-.073(.300)$ \\
Nervous and stressed & 260 & 5 & 1 & 6 & $2.51(.077)$ & 1.247 & 1.556 & $.858(.151)$ & $.375(.301)$ \\
Frustrated career opportunities & 262 & 5 & 1 & 6 & $2.21(.071)$ & 1.151 & 1.326 & $.909(.150)$ & $.505(.300)$ \\
Sense of denials and betrayals & 262 & 5 & 1 & 6 & $2.36(.077)$ & 1.242 & 1.542 & $.941(.150)$ & $.449(.300)$ \\
Summary Measure of Conflict & 253 & 42.00 & 10 & 52 & $23.95(.541)$ & 8.612 & 74.160 & $.541(.153)$ & $.059(.305)$ \\
\hline Source Surve
\end{tabular}

Source: Survey data, 2018.

Table 3 presents the ten scales used to capture data on inter-personal conflicts and shows the individual descriptive/distribution statistics- the mean, minimum, maximum, standard deviation, variance, range, standard error of the mean, as well as the kurtosis/skewness with their standard errors. The statistics were used to test the prevalence of conflict in the universities.

In spite of the strong wordings of the inter-personal conflict scales, Table 3 shows that mean scores of variables were close-knit, ranging between 2.22 and 2.55 on a scale of 1-6. The variance and standard deviations were also close, even as the standard errors of the mean estimates were relatively low. More importantly, the kurtosis statistics were all positive with very low standard errors, an indication that the observations cluster more around the mean and have longer tails. The skewness statistics were generally more than twice their standard errors, an indication of departure from symmetry. However, the summary measure of conflict shown in the last row of Table 3 satisfies the condition for symmetry, being less than twice the standard error. The foregoing descriptive statistics; which have moderate means, low standard deviations and significant clustering around the mean scores provide the evidence that the respondents returned an about average level of conflicts in the universities. Hence, the postulation in Hypothesis 2 that Nigerian universities are not characterised by a high incidence of conflict is false and is hereby rejected.

\subsection{The impact of Leadership Behaviour on Employee Engagement.}

Prior to relationship tests, each of the conflict and engagement measurement scales were jointly taken through factor analysis and were reduced to two empirical dimensions. Obtained were two categories of conflict interpreted as interpersonal conflicts and career frustration conflicts, as well as two dimensions of engagement were identified and interpreted as "Motivated" and "Satisfied".

\section{Table 4. Correlation test results of the dimensions of leadership, conflict and engagement}

$\begin{array}{lcccc} & \text { Inter-personal enmities } & \text { Career frustration } & \text { Motivated } & \text { Satisfied } \\ \text { Transactional behaviour } & -.159(.003) & & .172(.002) & \\ \text { Managerial behaviour } & & -.141(.009) & .347(.000) & .262(.000) \\ \text { Collegiate behaviour } & -.120(.027) & -.137(.012) & .292(.000) & .245(.000) \\ \text { Laissez faire behaviour } & -.259(.000) & -.243(.000) & .153(.006) & \\ \text { Inter-personal enmities } & 1 & & -.112(.032) & \\ \text { Career frustration } & & 1 & -.324(.000) & \end{array}$

Table 4 reports the significant correlations and the significance levels in bracket, obtained from the Pearson 2-tailed correlation tests. All the four leadership dimensions were found to have significant negative relationship with at least one out of the two conflict inclinations, while however, the collegiate and the laissez faire leadership behaviours have strong negative relationship with both dimensions of conflict. Likewise, all the four leadership behaviour types exhibit strong positive relationship with the "Motivated" component of engagement. Again, the managerial and collegiate behaviours relate more widely and positively with the two typologies of engagement. In effect, a unit improvement in the deployment of the leadership behaviours would cause a unit decrease on the conflict categories but a unit increase in the attainment of employee engagement. The foregoing findings are supported by regression tests, the results summarized in Table 5. The most important statistics are the $\mathrm{R}^{2}$ and F-ratio as measures of model fit, the $B$ statistics of each independent variable, the t-test of variance and the significance levels. 
The statistics in columns 2 to 4 provide the evidence of model fit whilst those in columns 6 to 8 show that the independent variables listed in column 5 have strong explanatory powers on the dependent variables listed in column 2. As a guide, $\mathrm{t}$ values higher than 2.0 accompanied by $B$ values (emboldened in Table 5) at $\mathrm{p}<0.05$ are considered significant for the purpose of making inferences. For purposes of parsimony, only those useful statistics are retained in Table 5. The Laissez faire leadership has a negative regression coefficient of -0.260 and -0.245 on inter-personal enmities and career frustration respectively. As well, the transactional and managerial leadership models have a respective influence of -0.160 and -0.143 on personal enmities and career frustrations. As well, all the leadership dimensions, but curiously except the laissez faire, exercised strong and positive regression effects on both dimensions of employee engagement.

Table 5. Summary of Regression results

\begin{tabular}{|c|c|c|c|c|c|c|c|}
\hline 1 & 2 & 3 & 4 & 5 & 6 & 7 & 8 \\
\hline $\begin{array}{l}\text { Dependent } \\
\text { variable }\end{array}$ & $\mathrm{F}$ & Sig & $\mathrm{R}^{2}$ & Independent variables & Beta & $\mathrm{t}$ & Sig. \\
\hline \multirow[t]{14}{*}{$\begin{array}{l}\text { Personal } \\
\text { enmities }\end{array}$} & 10.036 & .000 & .108 & Transactional & -.160 & -3.09 & .002 \\
\hline & & & & Collegiate & -.121 & -2.34 & .020 \\
\hline & & & & Laissez-faire & -.260 & -5.02 & .000 \\
\hline & & & & Managerial & -.143 & -2.76 & .006 \\
\hline & & & & Collegiate & -.138 & -2.66 & .008 \\
\hline & & & & Laissez-faire & -.245 & -4.72 & .000 \\
\hline & & & & Transactional & .148 & 3.025 & .003 \\
\hline & & & & Managerial & .315 & 6.552 & .000 \\
\hline & & & & Collegiate & .257 & 5.257 & .000 \\
\hline & & & & Career frustrations & -.207 & -4.27 & .000 \\
\hline & & & & Transactional & .117 & 2.098 & .037 \\
\hline & & & & Managerial & .291 & 5.336 & .000 \\
\hline & & & & Collegiate & .278 & 5.000 & .000 \\
\hline & & & & Career frustrations & .113 & 2.055 & .041 \\
\hline
\end{tabular}

Source: Field survey, 2018.

The foregoing correlation and regression results provide sufficient evidence to reject the position taken in Hypothesis 3 that leadership behaviour has no impact on employee engagement.

\subsection{The Moderating Impact of Conflict on the Leadership and Engagement Relationship.}

Path analysis through path analytic diagrams enables visual expression of cause and effect and allows for the computation of direct and indirect effects in a network of entity relationships. This provides a useful means of testing for the intervening influence of conflict on the leadership behaviour and employee empowerment relationship. Deriving from the regression results in Table 5, Figure 1 presents the path diagram of the cause and effect, in a step-wise format from which the direct and indirect connections between variables are computed.

Table 6 decomposes the path coefficients in Figure 1 into their direct, indirect (moderating) and total effects in columns two, three and four respectively. The indirect effect is the product of in-between coefficients between every pair of first and last variable connected by arrows (Anderson et al, 1995; Flynn et al, 1995a). For each leadership dimension listed in Table 6, the direct effect (Column 2) and the indirect effect (column 3) are summed up as the total effect (Column 4). The cell in the last row and column records the negligible figure of 0.043 as the sum of the positive and negative total effects rolled out in column 4. As if by a destructive attrition process, the robust influence of the leadership behaviours on the engagement dimensions were neutralized to near zero. Accordingly, there is no basis to accept Hypothesis 4; which states that conflict does not affect the leadership and engagement relationship. 
Table 6. Decomposition of regression coefficients

\begin{tabular}{lcccc}
\hline \multicolumn{1}{c}{1} & 2 & 3 & 4 & 5 \\
\multicolumn{1}{c}{ Leadership dimensions } & Direct effect & Indirect effect & Total effect & Engagement dimensions \\
Transactional leadership & 0.148 & - & 0.148 & \\
Collegiate leadership & 0.257 & -0.345 & -0.09 & Motivated \\
Laissez faire leadership & - & -0.452 & -0.452 & \\
Managerial leadership & 0.315 & -0.35 & -0.035 & \\
Transactional leadership & 0.117 & - & 0.117 & \\
Collegiate leadership & 0.278 & -0.17 & 0.108 & Satisfied \\
Laissez faire leadership & - & -0.028 & -0.028 & \\
Managerial leadership & 0.291 & -0.016 & 0.275 & $\mathbf{0 . 0 4 3}$ \\
Total impact of leadership behaviour on engagement as moderated by conflict & & & \\
\hline
\end{tabular}

Source: Field survey, 2018.

\subsection{Leadership behaviour, conflict and engagement across university and employee groups}

The ANOVA test procedure was applied to investigate differences across university and employee categories, as a means of testing Hypothesis 5. Several mean difference tests were conducted using the demographic sub-samples reported earlier in Table 1. The statistics there from are too voluminous to report here even as they do not add much value to the study. The ANOVA findings suggest that the results of the study apply universally across the sub-samples of universities and employees studied.

For example, Inter-personal enmities (one of the two conflict types) is the only one out of eight factor dimensions of variables in the study that varied significantly at $p=0.033$, the standardized mean scores being 0.259 for the federal universities, and -0.015 and -0.092 for the private and the state universities in that order. For all the study variables, Figure 1 shows three sub-samples of university types having bar charts of varying lengths, between 0.2 and -1.6 above and below the $\mathrm{X}$-axis, out of procedurally available +-0.5. For example, the positively longer length of the bar of transactional leadership implies greater manifestation in the state and federal universities. This contrasts sharply with the below the line negative bar chart of transactional leadership in the private universities even without a clearly distinguished type of leadership behaviour.

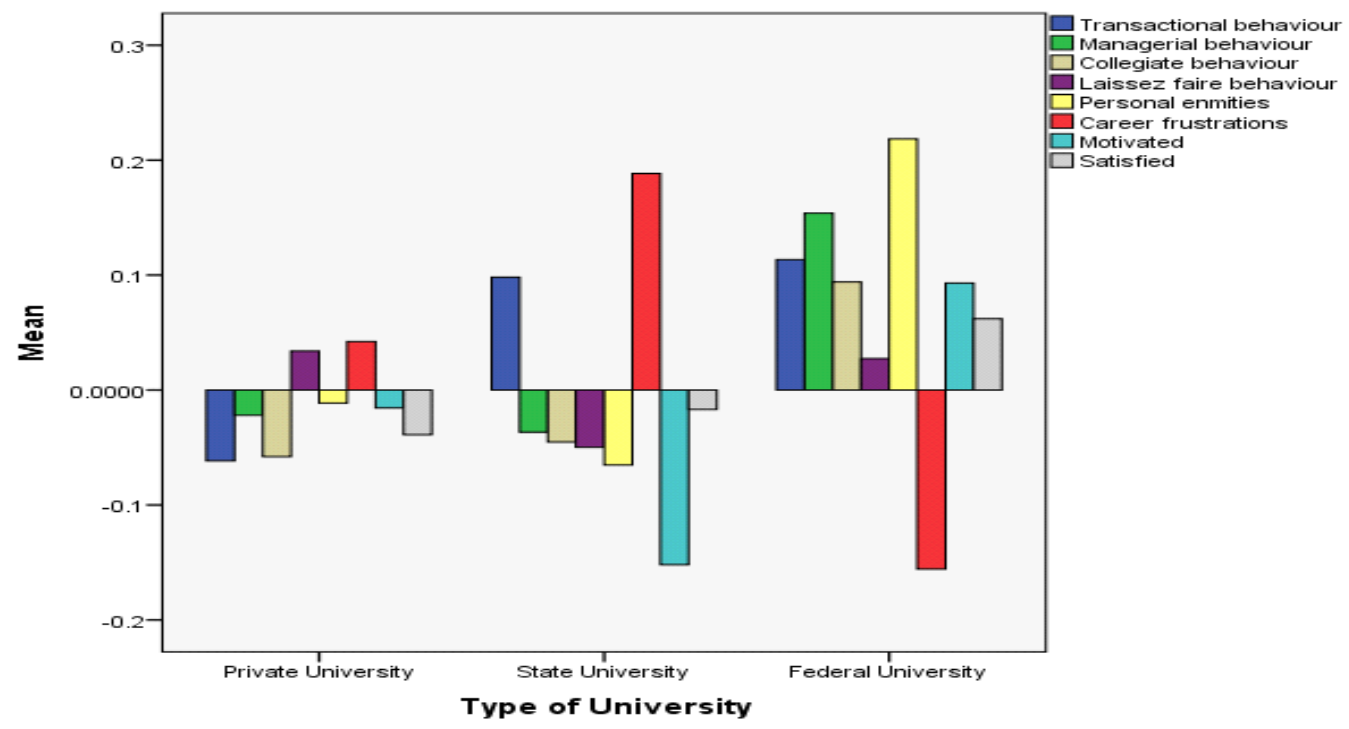

Figure 1. Clustered bar charts of Leadership, Conflict and Engagement across University types

Likewise, Figure 2 suggests superior emphasis on all of transactional, managerial and collegiate leadership in the federal universities. This enriched combination of especially the managerial and collegiate behaviours, whose superior impacts were justified earlier, appear to account for the uniquely and moderately positive bar charts of both categories of engagement- "Motivated" and "Satisfied" in the federal universities. Nevertheless, given that statistical estimates of these differences are largely insignificant as reported earlier, whilst the numerical values of most of the bars in Figure 2 lie within 0.00 and $|0.15|$ out of a maximum standardized mean score of $|0.5|$ that is procedurally available, the differences appear rather low, isolated and spurious. 


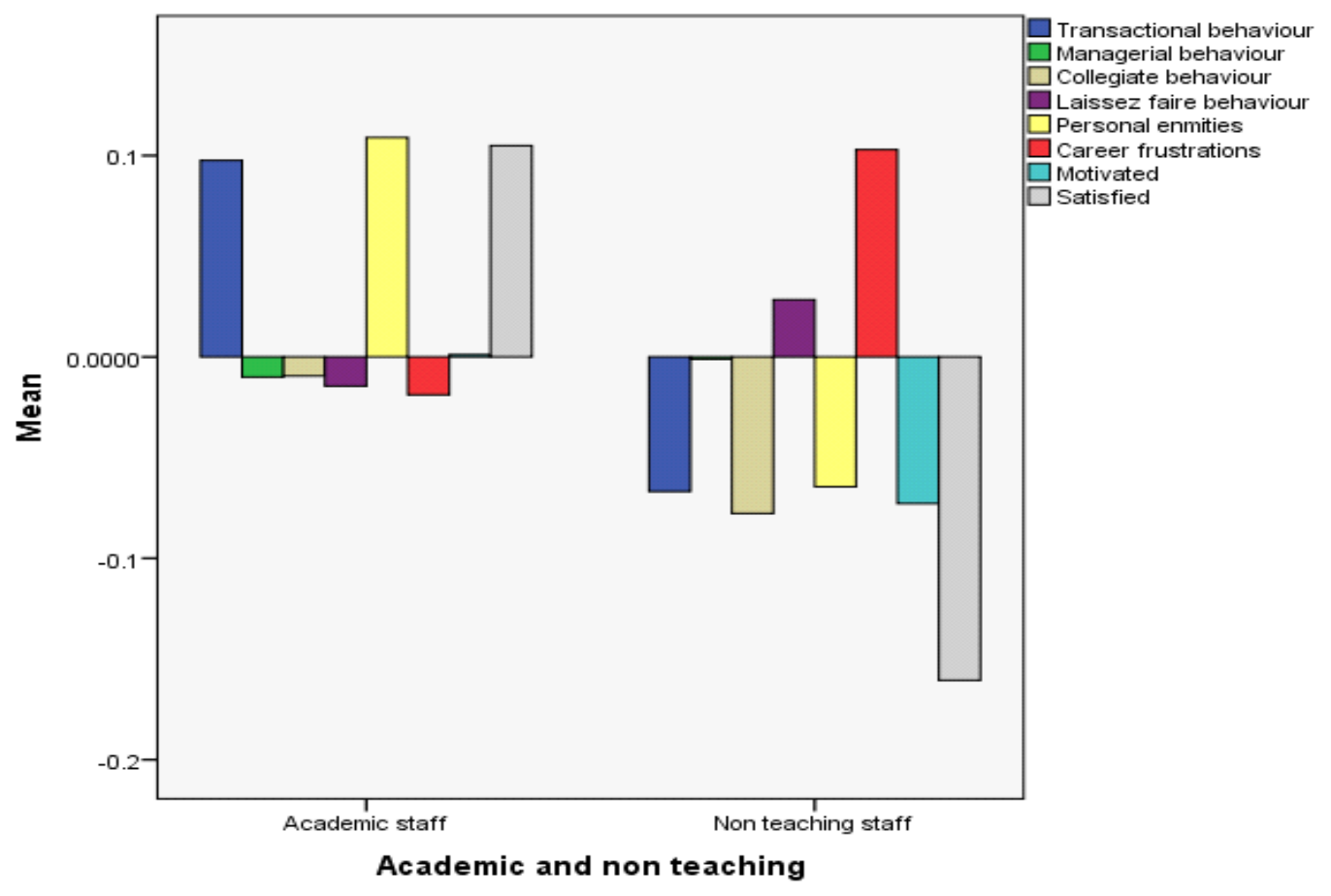

Figure 2. Chart of differences in leadership, conflict and engagement across employee groups

Similar result and conclusions emanate from the ANOVA test for differences across employee sub-samples. However, for the academic and non-teaching staff categorization, "Inter-personal enmities" (a conflict dimension) and "Satisfied" (an engagement category) returned significant differences at $p=0.031$ and $\mathrm{p}=0.011$ respectively. Inter-personal enmities has a standardized mean score of 0.108 for the academic staff and -0.12 for the non-teaching staff, whilst "satisfied" has a standardized mean score was 0.124 for the academic staff and -0.147 for the non-teaching staff. The clustered bar charts in Figure 2 further reveal this disparity. The academic staff group is differentiated by positively higher transactional leadership, inter-personal conflict and satisfaction whilst career frustrations typify the non-teaching staff. The empirical support for differences in the research constructs across university and employee categories is not widespread, even as the differences were generally weak. There is therefore no basis to reject the Hypothesis 5 of no difference in the perceptions on leadership behaviour, conflict and engagement across the university and employee groups studied.

\section{- Discussion}

The results from the foregoing data analyses support the hypotheses of the study. One major objective was to examine leadership behaviours, four of which were identified- transactional, laissez-faire, collegiate and managerial. The results reveal that Nigerian universities experience a rich mix of leadership behavioural styles associated with the Western Europe and American universities. For instance, Bergquist (1992) found four dominant leadership types in American higher education, namely collegiate, managerial, developmental and transactional. However, perhaps due to differences in competitive and inspirational pressures, the laissez-faire model replaces the developmental style in Bergquist's work. The results also demonstrate the superiority of the collegiate and managerial leadership behaviours; which have stronger and more widespread impacts on conflict and engagement. Bergquist (1992) reported similar results. The second objective was to measure the impact of leadership behaviour on employee engagement. The results obtained from Hypothesis 2 show that a positive improvement on any of the leadership dimensions, especially the collegiate and managerial categories generate a plus on both dimensions of employee engagement- "Motivated" and "Satisfied". These findings are in tandem with several previous works. For instance, in a study of a large insurance company in New Zealand (Xu and Thomas, 2011) and the Egyptian banking sector (Ahmed \& Dajani, 2015), three leadership behaviours- team-based (collegiate in this study), performance-oriented (managerial here) and relationship-centred (transactional at this point) were found to be the most important drivers of employee engagement.

The most important objective however was to investigate the impact of conflict on the leadership and engagement relationship (Hypothesis 4). The results show that the strength of the leadership behaviour categories on both dimensions of employee engagement were reduced to a negligible value of 0.043 . 
Conflict, especially those arising from career frustrations could turn employees to enemies within the boss-subordinate relationship, even as those caused by inter-personal enmities generate grapevines for retaliatory, destructive and inhibitive games. In the ivory tower context where results are less tangible and measurable in the short run, years of rot may become manifest rather lately and become too deep to tackle. Curseu (2011) reported similar results showing that leadership efforts to steer effective teamwork processes, results and loyalty come to nought when task and relationship conflicts come into play. This study is an effort in the call (Curseu, 2011) for empirical work on conflict leadership.

The last objective was to tests for demographic differences in the results (Hypothesis 5), none of which were validated across universities and employee cadres. The study therefore failed to effectively differentiate the state/federal universities financed by government from the privately-funded ones. This is in spite of the expected entrepreneurial and vision-driven pressures for greater accountability, quality, results and sustainability expected of the latter. Worse still, insidious but open secret reports abound on unwholesome employment, accreditation and governance practices by private universities (Adeleye, 2015; Okebukola, 2018).

The study presents some theoretical and practice implications for conflict leadership towards greater attainment of employee engagement. As all the identified leadership behavioural styles fall within the popular domain and were devoid of trade-offs in their impacts on the dependent variables, it means that convergence is possible in spite of the reported explosion and confusion in leadership research (Yukl, 1989; Bergquist, 1992; Grint, 2015). Further research is required to explore frameworks for synthesis, integration and counter-balancing of a range of leadership behaviours (Bergquist, 1992). The results also suggest that effective leadership should be seen as conflict leadership (Shetach, 2012; Offord, et.al., 2016). Otherwise, efforts towards greater goal realization could be in vain if organizations focus on bottom line performance issues rather than the reduction of the incidence and magnitude of conflict at work.

\section{Acknowledgement}

We express gratitude to the respondents who accepted, competed and returned our questionnaires. Our thanks also go to Mrs. Kemi Fatona, Secretary to the Dean, Faculty of Humanities, who took time to do the data entry.

\section{References}

Adeleye, E.O. (2015). Impact of Leadership Behaviour on Job Satisfaction in Nigerian Public and Private Universities. The Interl Journal of Business and Management, 3(10), 520-530.

Ahmed, H. \& Dajani, Z. (2015). The Impact of Employee Engagement on Job Performance and Organizational Commitment in the Egyptian Banking Sector, Journal of Business and Management Sciences, 3(5),138-147.

Asawo, S. P. (2011). Corporate integrity and company-community conflict management in the Niger Delta region of Nigeria. Journal of Leadership, Accountability and Ethics, 8(3), 77-88.

Baatz, E.B. (1993). 'Motorola's Secret Weapon' Electronic Business April, 51-53

Barbuto, J., Phipps, K., \& Xu, Y. (2010). Testing relationships between personality, conflict styles and effectiveness. International Journal of Conflict Management, 21(4), 434-447.

Bass, B. M., \& Avolio, B. J. (1995). The Multifactor Leadership Questionnaire. Palo Alto, CA, Mind Garden.

Bass, B.M. (1985). Leadership and Performance beyond Expectations (N.Y., Free Press)

Bass, B.M., Avolio, B.J., Jung, D.I. \& Berson, Y. (2003)., "Predicting unit performance by assessing transformational and transactional leadership", Journal of Applied Psychology, 88, 207-218.

Bergh D.D., Ketchen D.J Jr., Boyd B.K. \& Bergh J. (2010). New Frontiers of the Reputation-Performance Relationship, Insights from Multiple Theories. Journal of Management, 36, 620-635.

Bergmann, H., Hurson, K. and Russ-Eft, D. (1999). Everyone a Leader: A grassroots model for the new workplace. New York: John Wiley and Sons.

Bergquist, W. H. (1992). The four cultures of the academy, Insights and Strategies for Improving Leadership in Collegiate Organizations. A publication of the Professional and Organizational Development Network in Higher Education. San Francisco, Jossey-Bass Inc.

Bolman, L.G., \& Deal, T.E. (2003). Reframing organizations ( $3^{\text {rd }}$ ed.). San Francisco, Jossey-Bass.

Bryman (1992), Charisma and Leadership of Organizations. London, Sage Publications.

Catteeuw, F., Flynn, E., and Vonderhorst, J. (2007). Employee engagement: Boosting productivity in turbulent times. Organisational Development Journal, 25, pp. 151-156.

Chaleff, I. (1995). The Courageous Follower. (San Francisco, Berret-Koehler.

Cresswell, J. W. (2008). Research design, qualitative and mixed methods approaches. Thousand Oaks, CA: Sage.

Curşeu, P. L. (2011). Intra-Group Conflict and Teamwork Quality, The Moderating Role of Leadership behaviours, Administrative. Sciences, 1, 3-13. 
Dalati, Serene (2014). Leadership Behaviours in Higher Education in Syria, European Conference on Management, Leadership \& Governance, November. Kidmore End, Academic Conferences International Ltd.

Daramola, A. G. \& Amos, T. T. (2016). Management and leadership in Nigerian universities. FUTA Journal of Management and Technology, 1, 1-16.

Dess, G.G. \& Picken, J.C. (2000). 'Changing Roles, Leadership in the $21^{\text {st }}$ Century', Organizational Dynamics Winter, 1834.

Ebura, V. O., Udida, L. A., Ekpiken, W. \& Bassey, U. U. (2009). Reinventing the Nigerian Universities' dream and the challenge of leadership. Conference paper presented at the 11th International Conference of Educational Management Association of South Africa (EMASA), $7^{\text {th }}-9^{\text {th }}$ August, 2009.

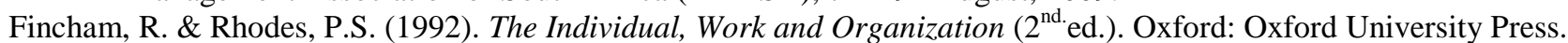

Grint, K. (2015). Literature Review on Leadership. Commissioned by, The Performance and Innovation Unit of the Cabinet Office. Retrieved from www.raf.mod.uk/.../1e91ecbb 5056 a318 a886ba6381c7554a.doc. 31/7/2015, 13.33 .

Health and safety Executive (2012). A review of the literature on effective leadership behaviours for safety (Research Report). Retrieved from www.hse.gov.uk/research/rrpdf/rr952.

Kelley, R. (1992). The Power of Followership. New York: Doubleday Currency.

Kihara, P., Bwisa, H. \& Kihoro, J. (2016). Nexus between Leadership Styles and Performance of Small and Medium Manufacturing Firms in Kenya. British Journal of Applied Science \& Technology 18(3), 1-13.

Luthans, F. \& Doh, J.P. (2009). International Management. Culture, Strategy and Behaviour. New York: McGraw-Hill.

Meindl, J.R. (1995). The romance of leadership as a follower-centric theory, A social constructionist approach. The Leadership Quarterly, 6(3), 329-341.

Montes, C., Rodríguez, D., \& Serrano, G. (2012). Affective choice of conflict management styles. International Journal of Conflict Management, 23(1), 6-18.

Ndum, V. E. \& Okey, S.M.(2013)., Conflict Management in the Nigerian University System. Journal of Educational and Social Research, 3(8), 17-23.

Northouse, P. (2004). Leadership Theory \& Practice ( $3^{\text {rd }}$ ed.). California: Thousand Oaks.

Obasi, I. N. (2007). Analysis of the Emergence and Development of Private Universities in Nigeria (1999-2006). Council for the Development of Social Science Research in Africa, 5 (2 \& 3), pp.39-66.

Odia, L. O. and Omofonmwan, S. I. (2007). Educational system in Nigeria: Problems and prospects. Journal of Social Sciences, 14(1), pp. 81-86.

Offord, M., Gill, R, \& Kendal, J. (2016). Leadership between decks. A synthesis and development of engagement and resistance theories based on evidence from practice in Royal Navy warships. Leadership and Organization Development Journal, 37 (2), 289-304.

Ojo, Olu (2009). Leadership behaviour and Organisation Transformation, A Theoretical and Empirical Analysis. Annals of University of Bucharest, Economic and Administrative Series, 3, 185-199.

Okebukola, P.A. (2018) Private Universities and the Revitalization of the Nigerian University System, Paper presented at the 10th Convocation lecture of Ajayi Crowther University, Thursday, 18th October [Brochure]. Nigeria: Ajayi Crowther University, Oyo.

Ogunruku, A.O. (2016). University Administration in an Emerging Democracy. 1st Annual Registry Lecture Series [Brochure]. Nigeria: Elizade University, Ilara-Mokin.

Papalexandris, N. \& Galanaki, E. (2008). Leadership's impact on employee engagement. Difference among entrepreneurs and professional CEOs. Leadership and Organisational Development Journal, 30(4), 365-385.

Raeve, L. D., Jansen, N. W. H., Brandt, P. A., Vasse, R. M., \& Kant, I. (2008). Risk factors for interpersonal conflicts at work. Scandinavian Journal of Work, Environment \& Health, 34(2), 96-106.

Salako, C. T. (2014). Challenges facing university education in Nigeria: The way forward. Journal of Educational Foundations, 4, 10-21.

Shetach, A. (2012). Conflict leadership, Navigating toward effective and efficient team outcomes. The Journal for Quality and Participation, 35(2), 25-30.

Vroom, V.H. \& Yetton, P.W. (1973). Leadership and Decision-Making. Pittsburgh: University of Pittsburgh Press.

Williamson, O.E (1975). Markets and Hierarchies, Analysis of Antitrust Implications. New York: Free Press.

$\mathrm{Xu}$, J. \& Thomas, H.C. (2011). How can leaders achieve high employee engagement? Leadership and Organization Development Journal, 32(4), 399-416.

Yukl, G. (1989). 'Managerial Leadership, A Review of Theory and Research.' Journal of Management 15 (2), 251-289.

Zimmerman, B. (1999). 'Complexity Science, A route through Hard Times and Uncertainty'. Health Forum Journal, 42 (4), $42-47$. 